\title{
UMA GOTA DE SUOR E O UNIVERSO DA EDUCAÇÃO FÍSICA: UM OLHAR SEMIÓTICO PARA AS PRÁTICAS CORPORAIS
}

\author{
Mauro Betti* \\ Pierre Normando Gomes-da-Silva** \\ Eliane Gomes-da-Silva***
}

\section{RESUMO}

Este ensaio problematiza possíveis relações da Semiótica, entendida como ciência que investiga a vida dos signos, com a Educação Física. Com destaque para a Semiótica ou Lógica Geral dos Signos elaborada por Charles S. Peirce (1839-1914), apresenta seus fundamentos, implicações e aplicações para as pesquisas no campo da Educação Física. Conclui que a Semiótica permite lançar novos olhares epistêmicos para a análise e intervenção na Educação Física, permitindo: compreender todas as suas manifestações como expressivas, significativas e comunicativas; rever as dicotomias presentes na Educação Física; reivindicar a ampliação do olhar para os sujeitos, condutas e situações motrizes como produtoras de linguagem, e, portanto, de comunicação com o mundo.

Palavras chave: Semiótica. Educação Física. Comunicação. Mediação.

\section{INTRODUÇÃO}

A única viagem verdadeira, a única fonte da juventude, não seria ir em direção a novas paisagens, mas ter outros olhos, ver o universo com os olhos de outro, de cem outros, ver os cem universos que cada um deles vê, que cada um deles é. (Marcel Proust) ${ }^{1}$

Poderia a Semiótica ï entendida como ciência que investiga a vida dos signos - ter outros olhos para a paisagem de impasses, divisões e dicotomias da discussão epistemologia e das práticas de trabalho acadêmico na Educação Física? Poderia auxiliar cada um dos que re-partem o campo vê-lo com os olhos do(s) outro(s), a

Docente do Departamento de Educação Física, Faculdade de Ciências, da UNESP, campus de Bauru e do Programa de Pós-graduação em Educação da UNESP, campus de Presidente Prudente.

** Docente do Departamento. de Educação Física, CCS/UFPB e do Programa de Pós-graduação Associado em Educação Física UPE/UFPB e do Programa de Pós-graduação em Educação-UFPB. Docente do Instituo Superior de Educação Orígenes Lessa (Lençois Paulista-SP) e doutora em Educação pela USP.

${ }^{1}$ PROUST, M. A prisioneira. São Paulo: Editora Globo,1994. 
"única viagem verdadeira", nas palavras do literato francês? Poderíamos todos ver a mesma Educação (Física), no singular e no plural? Estas são as perguntas de fundo deste artigo, mas não é seu objetivo respondê-las exaustivamente, senão indicar algumas possibilidades teóricas e resultados empíricos, simples notas introdutórias a partir de uma das tradições do campo semiótico; campo, aliás, pouco conhecido na Educação Física (EF).

Antes, porém, precisamos nos situar na própria EF, ponto de partida para o movimento que pretendemos realizar, pois permanecer no mesmo lugar, olhar a paisagem sempre da mesma perspectiva vicia a mente. Do mesmo modo que Betti, Ferraz e Dantas (2011), não perguntaremos o que é EF, mas o que fazem os seus profissionais. Respondemos: lidam com as dinâmicas de construção de significados que se dão nos processos de confronto dos sujeitos com as possibilidades do corpo em movimento no mundo (objetos, natureza, estruturas urbanas, pessoas, informações...) com propósitos educacionais explícitos e/ou implícitos, quer dizer, com intenção de produzir aprendizagens e influenciar a vida das pessoas. Algumas dessas possibilidades sedimentam-se como cultura num dado tempo histórico (por exemplo, jogos, exercícios físicos, esportes, acrobacias, ginásticas, danças, práticas corporais na natureza), e, portanto estão sujeitas ao dinamismo da cultura ï surgem novas, outras desaparecem, outras se modificam. Retomando agora as palavras de Betti, Ferraz e Dantas (2011, p. 106), os propósitos e as direções com que a Educação Física busca influenciar a vida das pessoas "dizem respeito a modos de ser e conviver, de pensar e conhecer, de apreciar e usufruir, de agirò e "mudam conforme mudam os contextos sócio-históricos (econômico, político, cultural, científico), as mentalidades e os interesses envolvidos", e também, acrescentamos nós, conforme muda nosso ecossistema biogeoquímico,

Todavia, tal investida não nos parece suficiente, é preciso buscar fundamentos ontológicos para a EF. E o que se pode identificar nas diversas situações de movimentar-se humano no trabalho, no lazer, nas liturgias religiosas, nas performances artísticas. Trata-se de pessoas agindo no mundo; com diferentes intencionalidades (conscientes ou não), respondendo a determinados apelos do mundo, criando ações e inações.

O que propomos é a ousadia de pensar mais radicalmente. É preciso compreender que o objeto de investigação/intervenção da EF associa os processos fisiológicos e a significação cultural. A gota de suor que escorre na pele de um 
atleta, de uma criança que brinca ou de alguém que dança, faz parte de uma rede de comunicação - de enzimas, hormônios, sinapses nervosas, oxigênio, sensações, emoções, valores, conhecimento, contexto, cultura, meio-ambiente, indivíduo, espécie, povo, sociedade, nação, planeta, universo... Rede como conjunto de elementos que se entrecruzam, que mantém contato, gerando um ambiente complexo, integrado e mutável, denominado "bioecológico" por Brofenbrenner (1996). Ou ainda, em termos semiótico-comunicacionais, trata-se de uma concepção sistêmica que prima pela continuidade dos processos de informação e significação (MACHADO; ROMANINI, 2010).

Do ponto de vista semiótico, aquela gota de suor é signo, ela indica algo, está, para alguém que a interpreta, no lugar de algo mais complexo ì processos fisiológicos, psíquicos e sociais. Ou seja, a EF não pode se restringir a uma cultura corporal, nem a uma fisiologia do exercício, devemos pensá-la como o conjunto dos processos orgânicos/filogenéticos e sócio-históricos, presentes no movimentar-se mais espontâneo da vida cotidiana ou em movimentos corporais organizados em sistemas gestuais, como práticas sistemáticas e intencionadas, das ações circenses aos treinamentos resistidos ou funcionais.

Consideramos então, preliminarmente, a hipótese de que a Semiótica pode contribuir decisivamente para retomar a EF na perspectiva aqui apontada.

\section{SOBRE A SEMIÓTICA}

A Semiótica é a ciência dos signos, uma teoria da significação, comunicação e cognição, que investiga as condições, processos e multiplicação dos signos. $O$ signo está relacionado ao significar. Dizer signo, portanto, é dizer projeto de significação, informação, mediação e interação.

Os signos interconectam estados do mundo, portanto é entidade dinâmica, desenvolve-se num processo contínuo de significar. Assim como a gota se suor que escorre na pele de uma criança, atleta ou dançarino, também a estátua de Pelé no Maracanã, comemorando o gol com soco no ar, o designer da prancha de surf, são signos, porque designam algo, seja o ícone do futebol brasileiro, seja a indicação da modalidade e estilo do surfista. É a Semiótica que estuda estes emitentes (imagens,

objetos, palavras, ações...) emitindo mensagens. É uma área de conhecimento que estuda a vida dos signos, o modo como se organizam para significar, qualquer que 
seja o campo em que se manifestem, descrevendo e interpretando suas múltiplas linguagens.

Estamos propondo relacionar a Semiótica com a Educação Física, mas, a partir do panorama histórico apresentado por Nöth $(1995,1996)$, sabemos que a semiótica é um conhecimento antigo, utilizado pelos médicos na grega clássica como parte da diagnóstica ï sintomatologia-, ou pelos filósofos que elaboraram a ñeoria dos signosò a exemplo do modelo platônico, analisando a relação entre nome, ideias e coisas. Também foi elaborado no medievo com os teólogos, em cuja doctrina signorum o signo era entendido como veículo para a comunicação de qualquer tipo ī "sentido espiritual"ī, quando coisas (re)significam outras. A doutrina renascentista da Assignatura das coisas era uma espécie de deciframento dos signos deixados na forma de vestígios no meio ambiente. Essa doutrina das suposições, no século XVI, desenvolveu-se ao lado do Tratado do Signo de João de São Tomas (Jean Poinsot), que pela primeira vez encarou a semiótica como uma problemática autônoma, da qual todos os outros tipos de conhecimento dependem.

Em seguida, conforme apreendemos também em Nöth (1995, 1996), e em Deely (1990), com o Racionalismo e Empirismo, a semiótica passou a ser descrita apenas em categorias mentais: o signo é a ideia de uma coisa que representa a ideia de outra coisa, tornando o processo confinado à mente. Porém, com o lluminismo e a Fenomenologia, a percepção dos sentidos foi considerada r̃signo causalò (Condilac), não representativo, mas indicativo porque estabelece conexão entre o vivido e o pensado, seja se aproximando da realidade do mundo (Diderot), seja chamando a atenção para o signo mesmo (Husserl), evocando ideias.

A Semiótica foi sistematizada como ciência a partir do final do século XIX, com duas tradições: a europeia e a norte-americana. A tradição europeia é mais conhecida pelas ciências humanas, compreende os fenômenos sociais como textos culturais ou sistemas linguísticos não-verbais. Pertencente ao campo da linguística, Ferdinand de Saussure (Suíça, 1857-1913), denominou tal ciência de semiologia. Saussure (1974), analisa a língua como um processo de significação a partir da relação imagem acústica (significante) e conceito (significado) ï este é o signo linguístico. A significação está na articulação de uma expressão mais um conteúdo (ideia). É uma relação tricotômica, uma ñpalavraò simboliza um pensamento (r̃eferênciaò), que r̃se refereò ao aspecto do acontecimento. Compreende-se então que não há pensamento precedendo uma expressão pelo ato de enunciação, ou 
seja, não há ideias antes da aparição da língua. A função da língua não é a palavra, mas a interpretação tanto do discurso, quanto do mundo, visto que não há mundo sem que a língua o defina. Por isso a língua torna-se um sistema modelizante primário. Os desdobramentos teóricos daí decorrentes tomaram a estrutura linguística guia para analisar os modos de expressão aceitos numa sociedade como sistemas semióticos não-verbais. É o caso dos diversos estudos semióticos da cultura (da literatura às danças folclóricas), de Hjelmslev (Dinamarca); Propp, Jakobson, Mukarovsky e Lotman (Rússia); Barthes, Greimas (França); Eco (Itália). Desse modo, segundo Nöth (1996), Saussure provocou uma revisão da metodologia das ciências humanas, a exemplo da antropologia estrutural de Lévi-Strauss, da história das ideias de Foucault, da psicanálise linguística de Lacan e da filosofia textual de Derrida.

A outra tradição semiótica, cujo precursor foi Charles Sanders Peirce (EUA, 1839-1914), recentemente redescoberta pelas pesquisas cognitivas, parte da lógica num projeto de englobar todas as ciências. Compreende o universo físico, metafísico, psíquico ou social como processo de semiose - signos interconectandose a outros signos, numa cadeia interminável.

Optamos por apresentar nossas reflexões na perspectiva da semiótica de formulação peirciana porque é a partir dela que nós pensamos a EF para além das dicotomias, há muito estabelecidas: humanismo e tecnicismo; mente e corpo; ciências sociais e ciências exatas; positivismo e fenomenologia ou materialismo histórico-dialético; crítico e não-crítico; treinamento e pedagogia; subjetividade e objetividade; aptidão física e significação cultural; experiência laboratorial e conjectura filosófica; testes validados e análises do discurso.

Isso porque, diferente da tradição europeia, Peirce $(1974,1975,1995)$ apresenta uma complexa arquitetura filosófica, a partir de um inventário categorial, que contempla as dimensões estética, ética e lógica, propõe uma semiótica ou lógica geral dos signos com base em tricotomias. Esboçaremos aqui minimamente a semiótica peirceana, em termos de procedimentos analíticos que possam auxiliar na decifração da lógica das práticas corporais.

Em sua teoria do conhecimento, Peirce repudia o fundacionismo empiricista ou idealista, localiza que o conhecimento não parte dos dados indubitáveis da experiência sensória nem dos esquemas conceituais, mas da mediação sígnica. Insistia na necessidade da percepção como porta de entrada do conhecimento, mas 
considerava que esse conhecimento, gerado na experiência, denominado de julgamento perceptivo, só ganha valor quando alcança caráter de generalização, quando é testado na sua relação com outros julgamentos da percepção. Ou seja, o perceptível, para servir como conhecimento do mundo, necessita estar inalienavelmente atado ao contínuo do pensamento. Diz ele: "toda forma geral de reunir conceitos é, em seus elementos, dada na percepçãoò(PEIRCE, 1995, p.228).

Para apresentar essa continuidade entre um juízo perceptivo e um juízo abdutivo (inferência hipotética), Peirce recorre à mediação do signo, juntando dois opostos num esquema triádico. Entre o idealismo e o realismo ingênuo, esclarece que o próprio juízo perceptivo é determinado por um objeto independente do pensamento, uma condição externa que determina a interpretação. Há um mundo que não foi feito por nós, que se força sobre nós, impondo-se sobre nossos desejos. Entre o percepto e a externalidade existe uma mediação do signo, no qual o róbjetoò que está fora é transmutado pelo modo como o signo o re(a)presenta ou indica. Desse modo, nunca se rompe o vínculo entre o objeto externo e o signo, "pois o interpretante, ou criatura que o signo cria e na qual é interpretado, é também uma interpretação do próprio objetoò(SANTAELLA, 1998, p.115).

A Semiótica ou Lógica Geral dos Signos de Peirce nos propõe pensar a partir dessa moldura conceitual, nesse diálogo entre a facticidade, determinação que o mundo exerce sobre nossos sentimentos, vontades e pensamentos, e a subjetivação, força lógica em responder por inferência, deduções ou intuições a significação do mundo. Por isso, por exemplo, Gomes-da-Silva, P.N. (2011), em suas investigações semióticas, distingue aspectos dos esportes de quadra dos praticados na natureza. Aqueles constroem uma sensibilidade diferente destes, porque são diferentes os processamentos de informações do ambiente (estável na quadra de futsal, imprevisível na corredeira do rafting), e, principalmente, há diferentes disposições para agir no mundo, ou seja, "para mover-se criando e recriando sentidos, reorganizando o equilíbrio e preenchendo de significação o campo perceptivoò(GOMES-DA-SILVA, P.N. 2011, p. 37).

Permitam mais um exemplo do signo em ação (semiose), numa situação de jogo, que pode ser uma luta, dança ou esporte. Nessa situação, digamos uma jogada, golpe ou passo, há uma multiplicação de signos, gerando na comunicação uma produção de linguagem. A semiose acontece numa rede de interações, ou melhor, numa r̃zona comunicativaò como compreende Gomes-da-Silva, P.N. (2007), 
já que na situação de jogo tudo é comunicativo i não apenas a interação entre as pessoas, umas comunicando-se com outras, mas também a demarcação do campo, o implemento, a duração da partida, o placar, a indumentária, a bioquímica, a gota de suor...

Essa zona de comunicação é criada nas práticas corporais: ñTodo espaço torna-se ambiente de comunicação [...] a comunicação envolve a todos e os ultrapassa, criando um ambiente de intersubjetividade. Não é um provocando e o outro respondendo. Ambos se provocam e são provocados ao mesmo tempoò (GOMES-DA-SILVA, P.N., 2007, p. 74). O jogador decodifica os gestos do adversário (posição, postura, feição) e antecipa a jogada, surpreendendo-o. Por exemplo, no vôlei, os ñogadores de meioòestão atentos, aos gestos do ñevantadorò perguntando-se ǿnde vai ser o ataque?ô para antecipar a realização do bloqueio e assim interceptar a trajetória da bola. Essa tomada de decisão é signo, gerado por uma multidão de outros signos. Atenção, percepção, memória, tomada de decisão i trata-se de processo sígnico de mediação entre o externo e o interno, do julgamento perceptivo ao juízo abdutivo. A inteligência sensório-motora, intuitiva e abstrativa é acionada para a resolução de problemas na situação lúdica estabelecida. Essa linguagem, ou signagem ï como prefere Pignatari (1984), está presente em qualquer jogo que exija o mínimo de tática, que supõe r̃ processo de selecionar uma resposta em um ambiente de múltiplas respostas possíveisò (MATIAS; GRECO, 2010).

Vemos então que a Semiótica relaciona elementos sensíveis e inteligíveis, reunindo signos exteriores com meios interiores, sensações e cognições, gestos com ideias. De modo que a semiótica é tridimensional: é uma ciência, que originariamente estuda o fluxo contínuo dos signos no mundo; é um método analítico de sistemas sígnicos (sociais e naturais); é uma atitude em relação ao mundo: desejo de perquirir ou inquirir. E como esclarecer Peirce (1984, p.46), ñperquirir é reconhecer que ainda não tem conhecimento satisfatórioò Diferente de investigação que ñpressupõe uma busca determinada por algum vestígio, a inquirição é uma atividade aberta, que não pressupõe uma busca por algo definido; é um perguntar a fundoò (RODRIGUES, apud COSTA; SILVA, 2011, p. 21-22). É a atitude investigativa que caracteriza o personagem das crônicas de Arthur Conan Doyle Sherlock Homes: conhecer o mundo relacionando juízos perceptivos aos juízos abdutivos. Esta é a atitude semiótica, ratifica Eco e Sebeok (1991). 
A Semiótica para Peirce é sinônimo de Lógica, consiste em apreender os caracteres sígnicos com base na rexperiênciaò pelo processo de r̃observação abstrativà̀ que procura imaginativamente estabelecer modificações em um hipotético estado de coisas, então o examina e observa aquilo que imaginou. Esse raciocínio é a base de uma ciência de observação cujo propósito é investigar o que pode ser, não simplesmente o que é, no mundo real. Lembrando que rexperiênciaò para Peirce, é tudo aquilo que se esforça sobre nossa consciência, que se impõe ao nosso reconhecimento. Consciência ou mente não se confunde com razão, está é apenas sua camada mais superficial. De modo que, qualquer coisa que se produz na consciência é signo, é processo de mediação. E toda e qualquer produção e realização de sentido já é sistema de linguagem, é fenômeno semiótico, portanto Peirce nos leva a considerar toda e qualquer expressão humana como uma questão semiótica, desde uma gota de suor até os Jogos Olímpicos.

Assim, Peirce classificou os modos como os fenômenos aparecem à consciência denominando-os de: Um; Dois; Três. Segundo ele, essas categorias são as mais elementares e universais dos fenômenos, para as quais toda a apreensão fenomênica tende a convergir. A gradação de três propriedades do pensamento e da natureza são: qualidade (Primeiridade), relação ou reação (Secundidade) e representação ou mediação (Terceiridade). São níveis de apreensão das coisas pela consciência. A Primeiridade é o sentimento imediato; é o campo do possível; é a consciência aberta, compreendida como um estado de disponibilidade, um instante do tempo, uma impressão total e indivisível. A Secundidade é a experiência de esforço, privado da ideia de objetivo; é uma consciência de ação-reação; sentido de resistência, consciência de atingir ou ser atingida por um fato; é o campo do existente. A Terceiridade é a consciência sintética, reúne tempo, aprendizado e pensamento; é o campo da generalização, do hábito, da lei. Daí o conceito de signo de Peirce (1984, p. 142) ser tricotômico:

\footnotetext{
Um signo ou Representamem é um Primeiro que se põe numa relação triádica genuína tal para com um Segundo, chamado seu Objeto, de modo a ser capaz de determinar um Terceiro, chamado seu Interpretante, o qual se coloque em relação ao Objeto na mesma relação triádica em que ele próprio está, com relação a esse mesmo Objeto.
}

Esclarecemos ainda que interpretante não significa um intérprete humano, um sujeito cognoscente sobre um objeto cognoscível, mas é a lógica que opera nas relações sígnicas, é o processo de mediação com a realidade. O interpretante é 
mediação tanto ao traduzir um signo em seu objeto quanto ao representar e criar um signo mais desenvolvido, deflagrando outras relações triádicas de significação.

Portanto, conhecer o mundo e a si mesmo é produção de semiose, já que o significado de um signo é sempre outro signo, num fluxo incessante de pensamentos ad infinitum. A linguagem é entendida como potencialidade que os diversos sistemas de signos, uma vez organizados, dispõem para produzir informações. A mediação entre o real e a consciência (humana) é feita na e pela linguagem, mas como o fundamento da semiótica peirciana é cosmológico, e não antropocêntrico, o Universo é visto como potencial produtor de informações, cuja organização em linguagem possibilita a criação de cultura (e portanto a semiótica não é avessa à antropologia). Nessa tradição pansemiótica, o horizonte de pesquisa abrange tanto o cultural quanto as relações entre organismo e meio ambiente, seja zoossemiótica (comportamento animal), biossemiótica (processos microbiológicos) ou ecossemiótica (genéticos e evolutivos), conforme Sebeok (1978).

Nos meandros da dinâmica peirciana há três níveis de análise do signo: significação, referencialidade e interpretação. Conforme Santaella (2004, p. 5), o primeiro nível é o do signo em si mesmo, as suas propriedades internas, o "seu poder para significar"; o segundo nível é a "sua referência àquilo que ele indica, se refere ou representa" (objeto imediato e objeto dinâmico); e o terceiro diz respeito aos "tipos de efeito que está apto a produzir nos seus receptores, isto é, nos tipos de interpretação que ele tem o potencial de despertar" (interpretante imediato, dinâmico e final). É oportuno aqui lembrar, também junto com Santaella (2004), que Peirce ampliou a noção de signo para qualquer coisa que venha à mente, por isso não precisa ter a natureza de um pensamento bem formulado e comunicado pelas palavras (signo de Terceiridade), mas pode ser uma ação corporal ou um sentimento ainda indefinido (signos de Secundidade e Primeiridade).

Essas sucessivas tricotomias pensadas por Peirce correspondem-se, segundo Pignatari (1987). Na Primeiridade (qualidade, possibilidade), o signo em relação a si mesmo (nível da significação) é denominado "qualisigno", em relação ao objeto é "ícone", em relação ao interpretante é "rema". Na Secundidade (ação e reação, existência), o signo em relação a si mesmo é "sinsigno", em relação ao objeto é "índice", em relação ao interpretante é "dicente". Na terceiridade (generalização, lei), temos, respectivamente: "legisigno", "símbolo" e "argumento". 
A seguir, as combinações desses três níveis de signos geram dez classes², que por sua vez multiplicam-se ao se relacionarem umas com as outras, chegando então Peirce a 66 classes. São elas que estruturam os raciocínios, que podem ser dedutivos, indutivos e abdutivos. A dedução demonstra que algo deve ser, a partir de teorias já estabelecidas formula predicações testáveis pela indução, a qual busca fatos, sugere os experimentos que poderiam trazer à luz os próprios fatos para os quais a hipótese teórica apontou. A abdução sugere que algo pode ser, examina os fatos para delinear categorias heurísticas ou da hipótese, que supõem uma relação interrogativa com a experiência, que consideram o acaso. Portanto, a indução e a dedução estão incluídas na abdução, pois, a partir da sugestão de uma hipótese, a dedução propõe predicações a serem testadas pela indução, $O$ que Peirce demonstra é que os métodos dedutivo e indutivo são lógicas comprobatórias, que nada criam, ao passo que a criação é prerrogativa do método abdutivo.

As tricotomias também estabelecem os três modos de relação com o mundo, que são: estético (sentir sem qualquer razão ulterior), ético (agir no confronto entre eu e não-eu) e lógico (fazer inferências, estabelecer consequências ou agir conforme um hábito). Ademais, todos esses modos de significação descritos por Peirce produzem tanto crenças e hábitos (nível de Terceiridade) quanto dúvidas (nível de Secundidade). O hábito é definido por Peirce (1974, 1975), como uma regra ativa, uma ideia geral que ganha o poder de excitar reações; é uma tendência estabelecida para comportar-se de maneira semelhante, sob circunstâncias similares, no futuro, seja pessoas ou seres não-humanos. A crença é a disposição para agir, e a dúvida é a possibilidade da mente modificar seus hábitos e adquirir novos. Mudar de hábito é, pois, modificar as tendências de uma pessoa para a ação. E a tendência para mudança de hábito, processo desencadeado pela dúvida, deve estar necessariamente presente em qualquer sistema usuário de signo, porque essa é a única possibilidade da criatividade, da semiose continuar em movimento.

\footnotetext{
${ }^{2}$ São elas: Qualissigno Icônico Remático, Sinsigno Icônico Remático, Sinsigno Indicial Remático, Sinsigno Indicial Dicente, Legissigno Icônico Remático, Legisigno Indicial Remático, Legisigno Indicial Dicente, Legisigno Simbólico Remático, Legisigno Simbólico Discente, Legisigno Simbólico Argumento (PEIRCE, 1995, p.55-58).
} 


\section{IMPLICAÇÕES E APLICAÇÕES NA EDUCAÇÃO FÍSICA}

A semiótica nessa tradição peirciana nos oferece um referencial teóricometodológico para avançar em relação à concepção hegemônica de EF ï conforme já anunciaram Betti (1994, 2007); Gomes-da-Silva, E., Sant'Agostino e Betti (2005), Gomes-da-Silva, E. (2010) e Gomes-da-Silva, P.N. (2001) ï na qual imperam dicotomias e divisões: teoria versus prática; conceitual, atitudinal e procedimental; cognitivo, afetivo e motor; natureza versus cultura. A Semiótica permite lançar novos olhares para a análise e intervenção na EF. Permite compreender todas as suas manifestações como expressivas, significativas e comunicativas, discordando do entendimento que apenas os movimentos das danças ou rítmicos são expressivos.

Uma importante olhar semiótico peirciano no campo da Educação Física foi direcionado para os jogos e brincadeiras. Gomes-da-Silva, P.N. (2011), nos três níveis de interpretação, a partir de 28 classes de signos, analisou a cultura do jogo, descrevendo o substrato formal das características estéticas, éticas e lógicas da conduta lúdica. Concluiu que o jogo é o campo da experiência perceptiva que favorece a reinvenção do real, devido a provocação da sensibilidade para o mundo e a cognição criativa. Em outros trabalhos, o mesmo autor analisou desdobramentos das classes sígnicas em jogos e brincadeiras específicos.

Valendo-se apenas da categoria da Primeiridade, Gomes-da-Silva, P.N. (2012) analisou o potencial educativo do jogo de bola de gude de crianças de 6 a 12 anos. $O$ jogo foi problematizado em termos de qualissigno (qualidade), sinssigno (ocorrência) e legissigno (classe de jogos) do espaço/tempo do jogo, implemento e gestos dos jogadores. $O$ resultado foi que a partir da facticidade, as experiências vividas no jogo funcionam como lugar de reflexão motora (coordenação e ocupação no espaço), abstrativa (projeção tática, possibilidades e riscos), verbal (discussões em relação ao cumprimento das regras) e cultural (transmissão intergeracional).

Uma pesquisa na Secundidade foi empreendida por Gomes-da-Silva, P.N. (2005) na análise da referencialidade dos brinquedos e dos brincantes. A face simbólica dos brinquedos, ou seja, sua codificação social, foi descrita a partir de suas cores (gênero), substâncias (sociedade plástica) e funcionalidades (autômatos). A face indicial dos brinquedos foi relacionada ao modo como os brincantes o utilizam. Em sua energia libidinal, os brincantes agem como ŕsoberanosò sobre os brinquedos e repetem, numa agressividade necessária, a criação. O resultado é que a codificação não é assimilada pela cultura infantil, como 
se espera a comunicação de massa e que, portanto, o educativo do jogo não está na ação pedagógica do adulto, mas na mediação que este estabelece com os efeitos do brincar.

Outra pesquisa tratou da Terceiridade do brincar, e analisa a linguagem dos gestos dos jogadores (GOMES-DA-SILVA,P.; CAVALCANTI; HILDEBRANDT, 2012). Interpretando as posturas, fisionomia e movimentos em três jogos infantis (jogos livres) e três jogos adultos (de aposta) compreendeu que o jogador, independente da idade, da modalidade, do espaço/tempo e dos implementos, move-se num desempenho motor (esforço neuro-muscular) como um interpretante dinâmico $\check{~}$ efeito produzido na mente pelo signo. Em outras palavras, quando o jogador está absorvido pelo jogo, ele age respondendo a apelos emocionais internos (emoções antitéticas), recorre a hábitos e pensa numa lógica abdutiva. Assim, os gestos no jogo configura uma linguagem não informacional, mas estética; porque é de construção criativa e portadora de um pensamento energético rítmico.

Tomando a comunicação corporal como sistema sígnico, há investigações desta linguagem nas relações entre professores e alunos, a exemplo da pesquisa de Antério e Gomes-da-Silva, P.N. (2012), que analisou as repercussões pedagógicas dos gestos de -professores de Educação Física nas suas aulas. Revelou-se que a timidez e distância entre intencionalidade e expressividade comprometem a intervenção pedagógica do professor. Nesse sentido, numa pesquisa-ação, baseando-se na classe do Sinsigno Indicial Dicente,_partiu-se do entendimento que o primeiro efeito (dicente) que o professor produz na mente de seus alunos está na sua gestualidade (sinsigno indicial). Como o sinsigno é acontecimento e indicial, é signo cujo referente é contiguidade do corpo, foram promovidas oficinas de vivências corporais, abordando os aspectos gestuais, posturais e de exploração do espaço. Os resultados obtidos sugerem a capacidade comunicativa como um saber docente, a ser aprendido na formação inicial como um vocabulário corporal.

$\mathrm{Na}$ mesma direção de tomar o processo pedagógico como fenômeno comunicacional, Gomes-da-Silva, E. (2012) investigou como se dão, na prática pedagógica de professoras de educação infantil, as relações entre crença, dúvida, hábito e conduta futura. Em processo de pesquisa-ação, buscou desestabilizar as crenças das docentes, instaurar-lhes dúvidas e provocá-las a agir reflexivamente em prol de mudanças em suas condutas docentes, em direção às singularidades das crianças e seus processos de significação em situações de jogos e brincadeiras. 
Concluiu que a modificação de hábitos não se desenrola espontaneamente. Mesmo diante de reiteradas experiências de insucesso, muitas vezes um professor não muda sua perspectiva do assunto ou situação, e por isso não percebe a presença de outros elementos que the permitiriam interpretar e agir de modos diferentes. É preciso oportunizar aos professores experiências de confronto com o outro (no caso, as crianças em situações motrizes e a própria pesquisadora), que instaurem a dúvida (Secundidade), para a seguir enfrentar um processo de reflexão crítica e autocrítica. A alteridade precisa desencadear o processo reflexivo, já que nossa percepção analítica das coisas é fortemente marcada pelo nosso repertório sígnico atual, de modo que é preciso crivá-lo com outras percepções e entendimentos, para então admitir novos conhecimentos e condutas pedagógicas (Terceiridade).

\section{CONCLUSÃO}

A Semiótica, ao considerar como signos sentimentos e emoções (Primeiridade), ações e reações (Secundidade), discursos e pensamentos (Terceiridade), e analisar como eles se almagamam, aproximam ao sentir, o agir e o pensar. Ou, em outros níveis de teorização, poderíamos falar em conexões e interdependências da intuição, da experiência empírica e da formalidade lógica; ou da estética, da ética e da lógica. E sentir, agir e pensar a Educação Física pela Semiótica significa abrir possibilidades de diálogo para áreas que tradicionalmente estavam separadas. Pensar a ação motriz em si mesma, ou a prática corporal como um todo, como semiose, é abrir as possibilidades de pesquisa e de intervenção.

Os estudos aqui descritos permitem vislumbrar ampliação e aprofundamento para outras práticas corporais e situações de ensino e aprendizagem na Educação Física. As experiências perceptivas de movimento, vivenciadas num treino desportivo, numa aula de Educação Física, ou numa sessão de relaxamento, podem ser desdobradas em seus vieses fisiológicos, pedagógicos, culturais, midiáticos. $\mathrm{Na}$ perspectiva semiótica, tanto a resposta dos marcadores fisiológicos do atleta quanto a verbalização dos alunos ao final da aula compreendem níveis de cognição, tão importantes no processo de adaptabilidade, mediação do viver, de modo não linear, senão complexo e criativo.

Ao compreendermos o motor relacionado com o simbólico e o lógico imbricado no físico, passamos a sistematizar práticas corporais, em suas relações comunicativas, na atenção ao atleta/aluno/⿳亠㐅⿵冂onsumidorò e ao 
técnico/professor/treinador, como produtores e intérpretes de signos, portanto, capazes de produzir conhecimento sobre si e sobre o mundo. O espaço de aula, de treino, de jogo, de prática, será entendido como partícipe da comunicação e formação do sujeito praticante. Os implementos serão analisados como importantes na execução do gesto, como também na rede de relações e simbolizações estabelecidas, conscientes e inconscientes.

Enfim, a Semiótica aponta à Educação Física que sujeitos, condutas e situações motrizes reivindicam para si uma melhor percepção e interpretação. Inclusive a gota de suor que escorre na pele do atleta, da criança que brinca, de alguém que dança.

\section{REFERÊNCIAS}

ANTÉRIO, D.; GOMES-DA-SILVA, P.N. Corpo comunicativo: analisando a comunicação corporal por meio do educador. Vivência, v.1, n.40, p.183-198, 2012.

BETTI, M. O que a semiótica inspira ao ensino da educação física. Discorpo, n.3, p. 25-45, 1994.

. Educação física e cultura corporal de movimento: uma perspectiva fenomenológica e semiótica. Rev. Física/UEM., v. 18, n.2, p. 207-217, 2007.

BETTI, M.; FERRAZ, O. L., DANTAS, L. E. P. B. T. Educação Física Escolar: estado da arte e direções futuras. Rev. Brasileira de Educação Física e Esporte, v.25, p.105 $-115,2011$.

BRONFENBRENNER, U. A ecologia do desenvolvimento humano: experimentos naturais e planejados. Porto Alegre: Artes Médicas, 1996.

COSTA, P. H. S.; SILVA, M. F. de A. O método pragmático de Charles S. Peirce. Metávoia, n.13, p. 19-32, 2011.

ECO, U. Tratado geral de semiótica. 3.ed. São Paulo: Perspectiva, 2000

ECO,U.; SEBEOK, T. O signo de três. São Paulo: Perspectiva, 1991

GOMES-DA-SILVA, E. Educação (física) infantil: a experiência do se-movimentar. ljuí: Ed. Unijui, 2010.

. Movimento e educação infantil: uma pesquisa-ação na perspectiva semiótica. 2012. Tese (Doutorado em Educação) - Faculdade de Educação, Universidade de São Paulo. São Paulo, 2012. 
GOMES-DA-SILVA, E.; SANT'AGOSTINO, L.H. F; BETTI, M. Expressão corporal e linguagem na Educação Física: uma perspectiva semiótica. Rev.Mackenzie de Educação. Física e Esporte, v.4, p.29 -38, 2005.

GOMES-DA-SILVA, P.N. Por uma ontologia do movimento comunicativo. In: GUEDES, O.C (Org.). Atividade física e esportes: contextos e perspectivas evolutivas. João Pessoa: Ed. Unipê, 2001, p.47-65.

Jogo, cultura e pulsão: uma semiótica dos brinquedos e dos brincantes. In: VITA, I.B.; ANDRADE; F.C.B.(Orgs.) (Des)fiando a trama: a psicanálise nas teias da educação. São Paulo: Casa do Psicólogo, 2005, p. 77-96.

A brincadeira de dar susto e o jogo da convivência. In: CAMINHA,I. (Org.). Aprender a conviver. João Pessoa: Ed. UFPB, 2007, p. 65-86.

- O jogo da cultura e a cultura do jogo: por uma semiótica da corporeidade. João Pessoa: Ed. UFPB, 2011.

A potência educativa do jogo da bola de gude. In: CAMINHA, I.( Org.). Inconsciente e educação. Curitiba: CRV, 2012, p. 105-134.

GOMES-DA-SILVA, P.N.; CAVALCANTI; K.; HILDEBRANDT,R. A poética dos gestos dos jogadores. Rev. Bras. Ciências do Esporte. v.27,n.2, p., 105-120, 2006.

MACHADO, I.; ROMANINI, V. Semiótica da comunicação: da semiose da natureza à cultura. Revista Famecos, v. 17 n. 2, p. 89 - 97, 2010.

MATIAS,C. J.; GRECO,P. J. Cognição e ação nos jogos esportivos coletivos. Ciência e Cognição, 2010, v.15, n.1, p.252-271.

NÖTH, W. A semiótica no século XX. 2.ed. São Paulo: Annablume, 1996.

. Panorama da semiótica: de Platão a Peirce. São Paulo: Annablume, 1995.

PEIRCE. C. S. Escritos coligidos. São Paulo: Abril Cultural,1974. (Os pensadores, 36)

. Semiótica e filosofia. São Paulo: Cultrix, Edusp, 1975.

. Semiótica. São Paulo: Perspectiva,1995

PIGNATARI, D. Informação, linguagem, comunicação. São Paulo: Perspectiva, 1968.

Semiótica e literatura. São Paulo: Cultrix, 1987.

SANTAELLA, L. A teoria geral dos signos. São Paulo: Pioneira Thomson, 2004.

. Semiótica aplicada. São Paulo: Pioneira Thomson, 2004. 
SAUSSURE, F. Curso de linguística geral. 4.ed. São Paulo: Cultrix, 1972.

\title{
A DROP OF SWEAT AND THE UNIVERSE OF PHYSICAL EDUCATION: A SEMIOTIC LOOK AT BODILY PRACTICES
}

\begin{abstract}
This essay raises problems around the possible relationships of Semiotics, understood as science that investigates the life of signs, with Physical Education. It emphasizes the Semiotics or the General Logic of Signs elaborated by Charles S. Peirce (1839-1914), and presents its fundamentals, applications and implications for research in the field of Physical Education. It concludes that Semiotics allows launching new epistemic looks at the analysis and intervention in Physical Education, in order to: comprehend all its manifestations as expressive, meaningful and communicative; review the existing dichotomies in Physical Education; claim for the enhancement of looking at the subjects, their conducts and living motion situations as producers of language, and, therefore, of communication with the world.
\end{abstract}

Keywords: Semiotics. Physical Education. Communication. Mediation.

\section{UNA GOTA DE SUDOR Y EL UNIVERSO DE LA EDUCACIÓN FÍSICA: UNA MIRADA SEMIÓTICA PARA LAS PRÁCTICAS CORPORALES}

\section{RESUMEN}

En este ensayo se problematiza la posible relación de Semiótica, entendida como ciencia que estudia la vida de los signos con la Educación Física. Especialmente la semiótica o Lógica General de los signos elaborada por Charles S. Peirce (18391914) presenta sus fundamentos, implicaciones y aplicaciones para la investigación en el campo de la Educación Física. Concluye que la Semiótica permite lanzar una nueva visión epistémica para el análisis y la intervención en la Educación Física, permitiendo: comprender todas sus manifestaciones como expresivas, significativas y comunicativas; revisar las dicotomías presentes en la Educación Física; reivindicar la expansión de la mirada para los sujetos, conductas y situaciones motrices como productoras del lenguaje, y por lo tanto de comunicación con el mundo.

Palabras clave: Semiótica. Educación Física. Comunicación. Mediación.

\section{Endereço para correspondência:}

Mauro Betti

E-mail: maurobettiunesp@gmail.com 